\title{
The European Monetary Policy Responses During the Pandemic Crisis
}

\section{Pierpaolo Benigno ${ }^{1,2}$. Paolo Canofari ${ }^{3}$ (D) Giovanni Di Bartolomeo ${ }^{4,5}$. Marcello Messori ${ }^{6}$}

Accepted: 4 February 2022 / Published online: 2 March 2022

(C) The Author(s), under exclusive licence to Springer Science+Business Media, LLC, part of Springer Nature 2022

\begin{abstract}
This paper uses an event-based analysis to describe how the European Central Bank's (ECB's) policy responses to the pandemic crisis have affected the European financial and economic system. The result of our exercise, which is based on the examination of the main measures taken by the ECB during 2020, is that these responses have positively affected the European economic system by improving banks' lending activity and by indirectly creating room for expansionary fiscal policies in the euro area's high-debt countries that do not have fiscal capacity.
\end{abstract}

Keywords Covid-19 ECB policy announcements · Financial market volatility · ECB policy reaction - Event-study analysis $\cdot$ Bank and government borrowing costs

\section{Introduction}

"The coronavirus (COVID-19) has produced a highly unusual recession and is likely to give rise to a similarly unsteady recovery" (Lagarde 2020a). The monetary policy implemented by the European Central Bank (ECB) to offset this extraordinary shock has been effective in improving banks' lending conditions for firms and households and has indirectly created fiscal capacity for high-debt countries in the Euro Area (EA). In particular, the paper shows the impact of these expansionary

\section{Paolo Canofari}

pcanofari@luiss.it

1 Department of Economics, University of Bern, Bern, Switzerland

2 EIEF, Rome, Italy

3 Dipartimento di Scienze Economiche e Sociali, Università Politecnica delle Marche, Ancona, Italy

4 Dipartimento di Economia e Diritto, Sapienza Università di Roma, Rome, Italy

5 Department of Economics, University of Antwerp, Antwerp, Belgium

6 Department of Economics and Finance, Luiss Guido Carli, Roma, Italy 
policy measures on the main spreads observed in the financial markets and on inflation expectations.

The ECB has utilised various instruments to ensure the effectiveness of monetary policy transmission mechanisms, to mitigate the fragmentation of financial markets and to facilitate liquidity provision to the banking sector in the EA. The present paper aims to analyse these instruments and to assess their specific economic impact. In this perspective, it aims to contribute to two strands of literature. The first strand examines the effects of the monetary policy designed to offset the impact of the Covid-19 shock on financial markets and the economy. ${ }^{1}$ The second strand relates to the use of event-study methodologies to examine the effects of monetary policy announcements. ${ }^{2}$ These methodologies have recently been extended to study the impact of unconventional monetary policies. ${ }^{3}$ In our work we mainly refer to Szczerbowicz (2015) and Altavilla and Giannone (2017), which focus on the monetary policies implemented by the ECB after the 2007-2008 financial crisis. Both papers show that announcements of some exceptional liquidity measures and the central bank's asset purchases have significantly stabilised financial markets and have lowered banks' refinancing costs and governments' financial charges. Our paper extends this approach to study the effects of the ECB's post-Covid-19 policies on bank lending and government borrowing costs.

The rest of the paper is organised as follows. Section 2 describes the main policy measures implemented by the ECB to overcome the Covid-19 shock. Section 3 complements the ECB's policy initiatives in 2020 with the ECB's announcements in the same year to build a string of monetary events. Section 4 provides a dynamic and qualitative view of inflation expectations and of the most relevant spreads in financial markets. Section 5, divided into three subsections, refers to an event-based analysis to assess the impacts of the ECB's policy measures on these spreads and on inflationary expectations. Section 6 concludes the paper.

\section{The ECB Policy Reaction to the Pandemic Crisis}

The ECB's policy response to the Covid-19 crisis has involved changes in the utilisation of the monetary channel as well as of the banking channel. The former has been characterised by the continuation of the Asset Purchase Programme (APP), its one-off strengthening, and the introduction and evolution of the Pandemic Emergency Purchase Programme (PEPP); the latter has been characterised by the introduction of new Longer-Term Refinancing Operations (LTRO) and by the repeated

\footnotetext{
1 See Benigno et al. (2020); Lane (2020a, b); Morelli and Seghezza (2021); Borri and Di Giorgio (2021) and Miller (2021).

${ }^{2}$ In this field, there is a rich set of papers that investigate the impacts of monetary policies on financial markets. See, among others Bernanke and Kuttner (2005); Gürkaynak et al. (2007); Gertler and Karadi (2015) and Gorodnichenko and Weber (2016); MacDonald and Popiel (2020).

3 See for example: Gagnon et al. (2011); Krishnamurthy and Vissing-Jorgensen (2011); Swanson (2011); Campbell et al. (2012); Hamilton and Wu (2012); Wright (2012); Rogers et al. (2014); Kuttner (2018); Sun (2020) and Swanson (2021).
} 
strengthening of the ongoing Targeted Longer-Term Refinancing Operations (T-LTRO III). ${ }^{4}$

Let us first list the changes in the banking channel by referring to three of the ECB's 2020 meetings. On 12 March 2020, the ECB introduced a temporary LTRO; then, on 30 April 2020, it launched a new LTRO programme (the Pandemic Emergency one: PE-LTRO). In these same meetings, the ECB strengthened its operating T-LTRO III. Finally, on 10 December 2020, it strengthened the new PE-LTRO and further reinforced the T-LTRO III.

The temporary LTRO can be considered a short-term liquidity bridge to cover the period preceding the starting date (24 June 2020) of the strengthened T-LTRO III. Following the initiative undertaken by the ECB in December 2011 and February 2012, this temporary LTRO was based on the ECB's liquidity supplies to the European banks with full allotment; however, this time the fix interest rate was set at the average deposit facility rate equal to $-0.50 \%$. Similarly, the PE-LTRO is characterised by the ECB's supply of liquidity which was adjusted to the amount demanded by the European banking sector at a negative interest rate equal to $-0.25 \%$, that is, at a fixed-rate determined by the average interest rate on the ECB's main refinancing operations decreased by 25 basis points. ${ }^{5}$ Originally, the PE-LTRO was based on seven refinancing operations to be taken in the period between May and June 2020 and to be closed by the end of September 2021 ${ }^{6}$; four additional operations were decided on 10 December 2020 and were implemented in 2021 with a "tenor of one year."

The strengthened T-LTRO III, which was the continuation of a programme launched in September 2019, aimed at providing for three-year refinancing of the European banking sector. ${ }^{7}$ It offered liquidity for a maximum amount of $50 \%$ of the eligible loan stock held in the balance sheet of each European bank at the end of February 2019. Moreover, it eased the collateral requirements until June 2021.

This new version of the T-LTRO III has improved the refinancing conditions for all the types of European banks grouped in three classes: the most, the median, and the less virtuous banks. The most virtuous banks have been refinanced at a rate equal to the average interest rate on the excess of bank reserves at the ECB (that is, $-0.50 \%)$ reduced by 50 basis points. In the period from mid-2020 to mid-2021, their consequent interest rate was equal to $-1 \%$; and this rate also set the maximum rate for their T-LTRO III refinancing during those twelve months. For refinancing preceding mid-2020 or following mid-2021, the interest rates were instead the average rates on the excess of bank reserves at the ECB in force for the duration of the debt

\footnotetext{
${ }^{4}$ The monetary policy roadmap described in the following section should be complemented with the main changes introduced in the European and international regulatory and supervisory framework. However, this goes beyond the scope of the present paper. See Gortsos and Ringe (2020) for a detailed presentation of these initiatives.

${ }^{5}$ Let us specify that the interest rates on the main refinancing operations are calculated along the duration of each specific loan activated by the PE-LTRO.

${ }^{6}$ These operations have a maturity between sixteen and eight months (September 2021 for the first operations, and July 2021 for the last).

${ }^{7}$ Here we refer to the April 2020 formulation and to the operations that began in June 2020 and should have been concluded by June 2021 .
} 
contract (-0.50\%). Between June 2020 and June 2021, the rate paid by the median virtuous banks was not higher than the corresponding average rate on the main refinancing operations of the ECB (that is, $0 \%$ ) reduced by 50 basis points. In the other periods, this class of European banks paid interest rates on refinancing equal to those in force on average. Finally, again from mid-2020 to mid-2021, the less virtuous banks obtained an interest rate equal to the maximum rate to be paid by the median virtuous banks.

As we have already recalled, the T-LTRO III was further improved in the meeting of 10 December 2020. The ECB decided to launch three additional refinancing operations from June to December 2021. It also decided to extend the most favourable interest rates and collateral conditions to June 2022; and it increased the maximum amount of refinancing that the European banks could borrow by fixing the threshold at $55 \%$ of their stock of eligible loans. However, only the most virtuous banks and those European banks able to meet "a new lending performance target" with respect to their previous class have benefitted from this improved condition.

Let us now turn to the monetary channel. As we have already mentioned, on 12 March 2020 the ECB decided to continue its APP, based on $€ 20$ billion purchases of financial assets per month, and to strengthen this programme by an overall temporary purchase of $€ 120$ billion in 2020. A few days later (18 March), the ECB launched the PEPP to allow the EA countries to relax their fiscal constraints and thus support firms' budget revenues and households' income through public transfers. At the beginning, the PEPP total envelope was $€ 750$ billion for purchases of the same types of assets included in the APP (mainly government securities) until the end of 2020. Hence, at first sight, this programme appeared to be an extension of the APP. However, there was an important difference in terms of flexibility: the monthly allocation of PEPP purchases of government securities among the various EA countries could deviate from the 'capital-key' rule even if, in principle, this rule had to be met at the end of the programme. ${ }^{8}$

The PEPP was strengthened at least twice. In the meeting of June 2020, the ECB decided to bring the total envelope of this programme to $€ 1,350$ billion and to extend its time horizon at least until the end of June 2021 or, if later, until the end of the pandemic impact on the EA economy. Moreover, in the same meeting, the ECB decided to reinvest the maturing principal payments from the securities purchased under the PEPP at least until the end of 2022. Then, in the ECB's meeting of December 2020, the PEPP's total envelope was brought to $€ 1,850$ billion and its time horizon was extended at least until the end of March 2022 or until the end of the negative economic effects of Covid-19. Moreover, the reinvestment of principal payments from the maturing securities purchased under PEPP was extended at least until the end of 2023.

\footnotetext{
8 The 'capital-key' rule is based on the shares of the ECB's capital held by each of the EU's national central banks. To be applied to the APP and PEPP, this rule requires the normalisation to 100 of the total shares held by the national central banks of countries belonging to the EA. The consequent reparametrised shares held by each of the EA's national central banks on the ECB's capital determine the portion of the national government securities to be purchased by the Euro-system of central banks.
} 
The abovementioned decisions underline that, in 2020 and in a large part of 2021, the ECB pursued clear forward guidance: the commitment to continue an expansionary utilisation of the monetary channels until the end of 2023. This strategy had an important side effect, that of easing the national fiscal policy constraints of the EA countries (particularly, those with a high public debt/GDP ratio) until the expiry date of the full spending commitments included in the National Recovery and Resilience Plans. The latter are the plans designed by the European Union (EU) Member States and approved by the EU Council in order to have access to the funds of the Recovery and Resilience Facility (RRF). ${ }^{9}$ In combination with the ECB's utilisation of the banking channel (see above), this shows the medium-term horizon of the current expansionary stance of European policies (common monetary policy, national fiscal policies, centralised - even if temporary - fiscal policy). However, as it was signalled by the ECB's meeting of December 2021, the expansion in the monetary policy could be slowed down in 2022 and 2023. Hence, it is crucial to specify the macroeconomic and financial impact of the decisions taken by the ECB before that date.

\section{The ECB's Announcements and the Monetary Policy Events}

The previous description of the ECB's initiatives in response to the Covid-19 crisis can be completed with a discussion of some of the announcements made by ECB President Christine Lagarde during the Press Conferences, which presented the decisions taken by the Governing Council in each of the 2020 ECB meetings. These announcements often influenced the impact of the undertaken monetary policies. ${ }^{10}$ However, it is difficult to offer a convincing ex-ante definition of the concept of "announcement" because, in the Press Conferences and other ECB documents, there are many statements that cannot be assimilated to this concept. For instance, all the policy measures described in the previous section were presented and discussed by the ECB's President and Vice-President, but the plain reference to these actual measures cannot be assimilated to an announcement. Many other cases are subtler. Hence, we need a judicious and parsimonious criterion of reasonableness for selecting the ECB's main announcements from the whole set of heterogeneous statements

\footnotetext{
9 The RRF is the most important programme of the Next Generation EU (NG-EU), which, in turn, represents a crucial EU innovation: the first partial implementation of a centralised fiscal policy based on the EU's debt issuances. The funds, allocated to the EU Member States through the RRF, amount to almost $90 \%$ of the total NG-EU envelope of $€ 750$ billion (at the 2018 price level). All these funds should be utilised by the end of 2026 but committed at the national level by the end of 2023 .

10 Appropriate policy announcements can reduce uncertainty; and this reduction has, in turn, positive impacts on the economic system in terms of investment, consumption, output, and worked hours (Bloom 2014; Baker et al. 2016; Basu and Bundick 2017). In this section, we show that the ECB has often been able to anticipate or support its policy decisions through appropriate announcements. This element corroborates the view that the discontinuities in the financial markets' volatility, which are approximated by uncertainty indicators, have been limited during the pandemic shock also thanks to the announced monetary policies (see also Benigno et al. 2020).
} 
made by the President and other Members of the Governing Council; and, obviously, this criterion cannot be based on the ex-post impact of each statement.

Despite the risk of getting trapped in circular reasoning, here we content ourselves with defining as "announcements" those statements which aim at affecting the expectations of market agents or which unintentionally but manifestly affect these expectations. In the following paragraphs, this criterion is used to analyse some of President Lagarde's words in 2020.

It is reasonable to believe that on 12 March 2020 Ms. Lagarde made an important announcement in the Q\&A session with the press when she stated: "The ECB is not "[...] here to close spreads. This is not the function or the mission of the ECB. There are other tools for that, and there are other actors to actually deal with those issues." The reason why this statement can be classified as a significant announcement is twofold. On the one hand, her reply to a journalist's question was based on a shared view of the independence of monetary policy. ${ }^{11}$ However, on the other hand, the timing for the reappraisal of this view was so inappropriate that the reply became a negative surprise. In those days, European citizens were watching on television the tragic lines of trucks transporting coffins with Covid victims in the most developed Italian region (Lombardy) and were realising that the health emergency was out of the European governments' control. The contradiction was so puzzling that President Lagarde had to adjust her statement a few hours later and the Governing Council had to immediately undertake new initiatives.

During the 29 October 2020 meeting, Ms. Lagarde made another statement that should be assimilated to an announcement. The ECB's President affirmed that, despite the wait-and-see position pursued by the Governing Council in the previous four months, new monetary policy initiatives were likely to be launched in the near future: "Staff macroeconomic projections in December 2020 will allow a thorough reassessment of the economic outlook and the balance of risks. Based on this updated assessment, the Governing Council will recalibrate its instruments, as appropriate, to respond to the unfolding situation." In the fall of 2020, there were - at least - three reasons that justify the classification of this statement as an announcement. The first reason was due to the unanticipated explosion of the second wave of Covid-19, resulting in prevailing expectations that further policy interventions were required. The second reason was based on Ms. Lagarde's choice of making a contingent but precise commitment on the conditions and the timing for strengthening the ECB's expansionary monetary policy: a negative economic outlook and the end of the year. The third reason depended on the international consensus in terms of the expected negative evolution of the European economy and, specifically, in terms

\footnotetext{
11 The question was: "at the moment certain countries are hit especially hard, like Italy. What can the ECB do if the spread for government bonds increases? [...] Could there be [...] possibilities to help certain countries?" In principle, Ms. Lagarde was right in referring to other policies. At different times, Draghi (2014); Visco (2019), and other members of the ECB Governing Council emphasised that monetary policy could not be the only "game in town" and could not be a substitute for pursuing the objectives of fiscal policy (a specific kind of 'fiscal dominance'). Hence, as Christine Lagarde, these policy makers maintained that monetary policy needs the support of an expansionary and centralised European fiscal policy during the economic crises.
} 
of a new recession during the fourth quarter of 2020 in the euro area. In fact, as we have already recalled, in the meeting of December 2020, the ECB strengthened its unconventional expansionary monetary policy through the monetary and banking channels.

By contrast, we maintain that it would be inappropriate to classify the repeated statements on the possible adjustments of the expansionary stance of the ECB's monetary policy to the actual economic changes as announcements. During the Press Conference of 30 April 2020, President Lagarde stated that the Governing Council was "fully prepared to increase the size of the PEPP" and "to adjust all of its instruments, as appropriate". The same concepts were repeated at the Press Conferences of 4 June and 16 July 2020, even if in a less assertive way. Then, despite the improved utilisation of all the tools of monetary policy, during the meeting of 10 December 2020 it was reiterated that the ECB Governing Council remained "ready to adjust all its instruments, where appropriate [...];" and analogous concepts were restated in a number of 2021 ECB meetings. We do not suggest classifying these affirmations as announcements because their content is self-evident and, contemporaneously, there was no specific commitment to undertake actual policy initiatives. Consequently, these affirmations are commonly viewed as being unable to have an intended or unintended impact on the expectations of market agents.

Assessing the statement first made by Ms. Lagarde during the Press Conference relative to the meeting of 21 January 2021 is more controversial. Before confirming that the monetary instruments would be utilised to "counter the negative pandemic shock to the path of inflation," the ECB's President claimed that "if favourable financial conditions can be maintained with asset purchase flows that do not exhaust the envelope over the net purchase horizon of the PEPP, the envelope need not be used in full." According to our definition of announcement, this last statement is ambiguous. It does not commit the ECB to specific initiatives, although it could be perceived as a surprise. However, considering that analogous statements were repeated in 2021 following meetings without any actual policy initiative, we have decided to exclude this aspect from the set of significant announcements. ${ }^{12}$

Table 1 dates the events that, following our discussion in the current and previous sections, have been identified as significant changes in the ECB's actual monetary policy and/or as significant announcements. This means that, in our framework, a significant monetary event can be based on two indicators: either the time in which new monetary policy decisions were undertaken, or the time in which new information was disclosed (announcement) regarding the policy stance. It follows that an event can refer to different ECB announcements or policy actions that occurred on the listed date.

\footnotetext{
12 This decision also justifies the reference to the 2020 announcements. In fact, the ECB's meetings from March to October 2021 did not introduce significant changes or announcements with respect to the EA monetary policy. Moreover, we do not have sufficient empirical evidence to assess the impact of the important decisions taken by the ECB in its meeting of mid-December 2021.
} 


\section{The Impact of the ECB's Pandemic Measures}

This section provides a view of the behaviour of relevant spreads in financial markets during the first two waves of the pandemic crisis. The analysis aims at illustrating the persistent effects of policy on longer horizons. ${ }^{13}$ In particular, Fig. 1 shows some indicators of the borrowing conditions of banks, firms and national governments, as well as the dynamics of inflation expectations. In the figure, we underline with vertical lines the events identified in Table 1. Panel (a) plots the long-term spreads on corporate and bank bonds; panel (b) illustrates the impact of ECB policies on government borrowing; panel (c) plots the market-based measures of expected long-run inflation in the EA. ${ }^{14}$

Panel (a) of Fig. 1 shows that, as the pandemic crisis erupted at the beginning of March 2020 with the first lockdown in Italy, spreads on corporate and bank bonds increased substantially, reaching levels higher than 250 basis points. At the beginning of 2021, both spreads came back to the pre-crisis levels, suggesting that ECB policies had been effective in reducing them. ${ }^{15}$ An examination of this figure produces other more specific and interesting observations. Following the 12 March 2020 event, the positive effect on both spreads - even if marginal - was reversed during the days after the announcement (an increase in both spreads was observed) when the market panicked as it digested Ms. Lagarde's Press-Conference remarks. Only the policy measures decided on 18 March 2020 were able to reverse this trend.

Panel (b) of Fig. 1 illustrates the impact of ECB policies on government borrowing conditions by considering the sovereign bond spreads' dynamics with respect to the risk-free counterparts at the same maturity. It focuses on the spread of the Italian debt and on that of a composite EA sovereign debt. The observed convergence of these two spreads suggests that this segment of the financial markets was stabilized by ECB policies. As noted, spreads remarkably increased after the start of the pandemic crisis and even more after the unfortunate Press Conference of 12 March 2020. However, it is evident that the decision to introduce the PEPP (18 March 2020) reduced the spreads on sovereign bonds until the beginning of 2021. Overall, the ECB's decisions on the PEPP (18 March and June 2020) together with the APP

\footnotetext{
${ }^{13}$ A thorough evaluation should rely on a proper econometric analysis, which falls outside the scope of this paper.

${ }^{14}$ More specifically, we refer to the following spreads: (i) the difference between a composite index of bank bonds and the 10-year swap rate; (ii) the differential between the yields of long-run BBB corporate bonds and the 10-year swap rate; (iii) the spread between a composite yield of the 10-year eurozone government bonds and the swap rate with the same maturity; (iv) the spread between nominal and real yields, and the swap rates at the same maturity (5 and 10-year inflation expectations). As a special case of (iii), the relevant spread is applied to the Italian government bonds.

${ }^{15}$ Lane (2020b) discusses the time series of the average euro-area lending rate, focusing on the intermediation wedge, i.e. the spread between the non-financial corporations' lending rate and the three-year swap rate capturing the risk-free rate. Lane shows that the ECB's overall action was useful to keep lending rates near historically low, by easing the terms and conditions on bank lending despite an increase in the credit risk. Therefore, a credit crunch was avoided. Borri and Di Giorgio (2021) also document that the PEPP announcement contributed to restoring calm in the European banking sector.
} 
Panel (a)

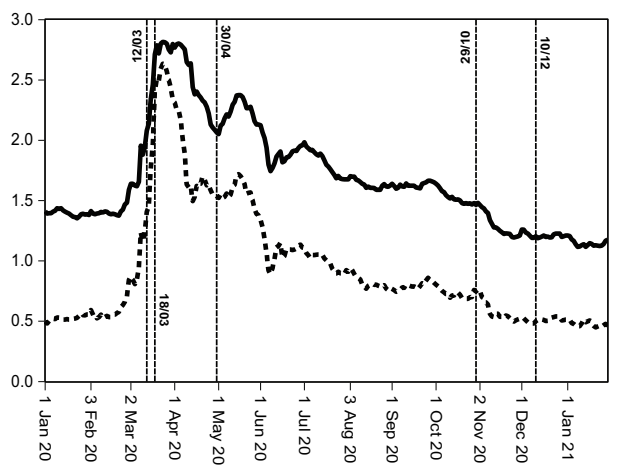

Panel (b)
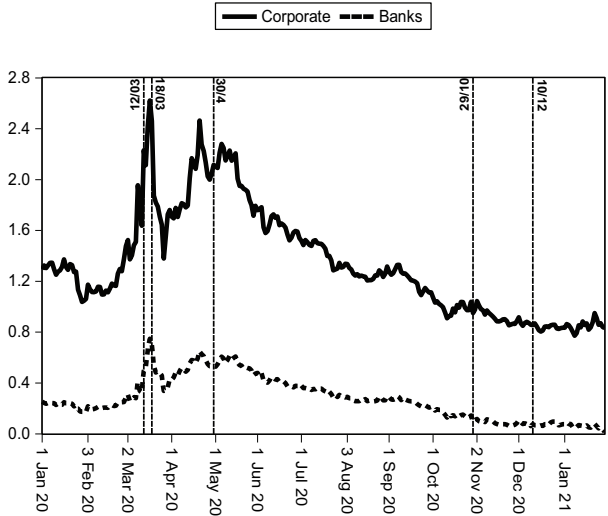

Panel (c)
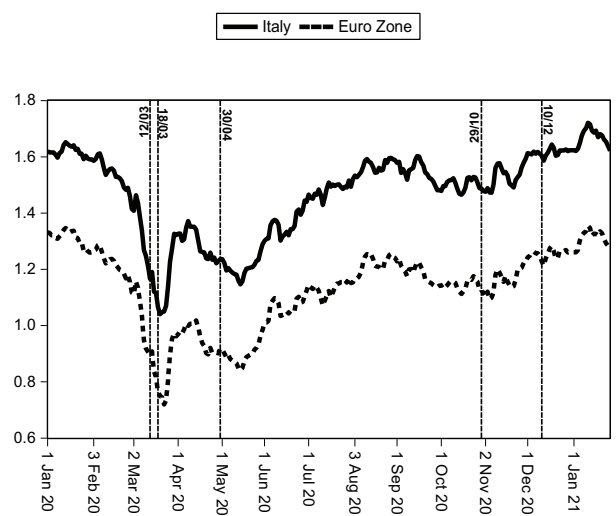

-10y10y --2 5y5y

Source: Datastream.

Fig. 1 Borrowing conditions and inflation expectations dynamics 
Table 1 Monetary policy events

Event \#1

12 March 2020

Event \#2

18 March 2020

Event \#3

30 April 2020

Event \#4

29 October 2020

Event \#5

10 December 2020
Having reached a zero-lower bound in policy interest rates some time before, the ECB implemented a strengthening of the T-LTRO III and a one-off enlargement of the APP. Moreover, President Lagarde announced that the ECB was not "here to close spreads" between government bonds of different EA countries, despite the exceptionality of the economic crisis.

The ECB enlarged the range of the eligible assets in the APP and implemented the PEPP. Moreover, it started to ease the quality of accepted collaterals.

The ECB further strengthened the T-LTRO III and implemented the PE-LTRO. The ECB Governing Council also announced that it would have been ready to provide additional liquidity, if needed. According to our previous analysis, this statement is not included in the announcements. However, the event remains significant in terms of policies.

The ECB announced the possible recalibration of its monetary policy instruments to counteract the projected negative inflation path and to support economic recovery, according to the new empirical evidence emerged in December.

The ECB implemented further strengthening of the PE-LTRO, the PEPP, the T-LTRO III.

Authors' elaboration on ECB's decisions and Press Conferences

scaling-up on 12 March have reduced the euro-area GDP-weighted ten-year sovereign yield by almost 45 basis points (ECB, 2020: Box 3). ${ }^{16}$

Panel (c) of Fig. 1 displays the two market-based measures of long-run inflation's expectations. On several occasions, ${ }^{17} \mathrm{Ms}$. Lagarde stressed that the introduction of the PEPP and the PE-LTRO, within the strategy already designed by the $\mathrm{ECB},{ }^{18}$ had provided crucial support for the resilience of inflation within the EA, preventing a much larger disinflationary shock and the risk of triggering a deflationary spiral at the end of 2014. Panel (c) shows that inflation expectations strongly declined from the outbreak of Covid-19 until the beginning of 2021 . On 23 March 2020 they reached a historical minimum of $0.72 \%$ over the 5 -year horizon and $1.05 \%$ over 10-year horizon. Following the 12 March Press Conference, the adoptions of the PEPP on 18 March and the PE-LTRO on 30 April 2020 were associated with a sharp increase in inflation expectations, especially for the very long-run component. However, some days were required for these announcements in order to affect the indicators in the "right" direction, perhaps suggesting that financial markets needed additional information to process the actual size of the monetary-policy stimulus.

A key factor of the positive reflationary reversal perhaps could have been traced back, at that time, to the beginning of concrete conversations on a common European fiscal policy reaction, thus boosting the stimulus provided by monetary policy. However, it is important to stress that market-based inflation expectations have still largely remained under the ECB $2 \%$ target, suggesting that all the policies

\footnotetext{
16 See also Lane (2020a, b).

17 See Lagarde (2020a, b).

18 See, e.g., Neri and Siviero (2018) and Rostagno et al. (2019).
} 
undertaken came short of reaching the ECB's long-term price objective. However, at the time this paper was written (December 2021), the five-year ahead forward swap rate had risen above $2 \%$. The President of the ECB and the majority of the Governing Council members still maintained that this excess in the EA's average inflation rate is a temporary phenomenon. However, in the meeting of mid-December 2021, the ECB decided to decelerate the expansionary stance of its unconventional monetary policy.

\section{The Impact of the ECB's Pandemic Measures: Quantitative Aspects}

This section assesses the impact of the policy measures implemented by the ECB to offset the pandemic crisis using an event-based analysis. This methodology allows us to refer to the descriptive analysis of the previous section and to closely examine the effects that the monetary policies, undertaken or announced by the ECB, had on relevant spreads in financial markets and inflation expectations as illustrated in Fig. 1. These variables are significant for the monetary policy's transmission mechanism during the pandemic shock. In doing so, we follow and extend the analysis provided by Szczerbowicz (2015), who instead analyses the monetary policies implemented after global financial crisis. ${ }^{19}$

\subsection{Methodology}

An event-based methodology allows us to assess the impact of the events considered on selected variables. We aim at evaluating how the ECB's 2020 unconventional and extraordinary monetary policy measures quantitatively impacted those two important aspects of the European economic processes whose changes were descriptively examined in Sect. 4, that is:

1) Borrowing conditions for different agents (banks, firms, and national governments);

2) Inflation expectations.

Borrowing conditions are key elements in the smooth functioning of the monetary policy's transmission mechanism. Inflation expectations are significant both as part of monetary policy transmission channels and as an indicator of the ECB's ability to reach its price stability objective.

We measure the impact of the ECB's extraordinary monetary policy initiatives on different variables (see Sect. 4).

\footnotetext{
${ }^{19}$ See also Altavilla and Giannone (2017). The same methodology has often been applied to studying financial markets under different perspectives, e.g. de Jong et al. (1992); Miyajima and Yafeh (2007); Ederington et al. (2015); Loipersberger (2018) and Sun (2020).
} 
1. Starting with the transmission in the banking sector, we consider measures of both short-term and long-term spreads in credit markets. These spreads highlight borrowing costs for banks. For the short-term spread, we make use of the differential between the 1-month (3-month) interbank rate captured by the EURIBOR and the 1-month (3-month) overnight indexed swap (OIS) rate, which is a proxy for the risk-free rate. For the long-term spread, we use the difference between the yield of a composite index of bank bonds and the 10-year swap rate capturing the long-term risk-free rate. ${ }^{20}$

2. Assessing then the transmission of the ECB's monetary policy (implemented or announced) to the corporate sector, we consider the spread between the yield of a composite index on BBB long run corporate bonds and the 10-year swap rate. ${ }^{21}$

3. As regards the national governments, we consider two cases: (i) the variation of the spreads between the yield of an index of 10-year government bonds of the eurozone countries and the swap rate with the same maturity as a benchmark; (ii) the spread between 10-year Italian government bond yield and the same benchmark.

4. Regarding inflation expectations, we use market-based measures: the spread between nominal and real yields and the swap rates at the same maturity. We consider 5 and 10-year inflation expectations.

The source of all the data is Datastream; and, given the events listed in Table 1, the sample period is January 2019-January 2021.

For each of the abovementioned variables, we run the following regression:

$$
y_{t}=\alpha+\sum_{1}^{m} \beta_{i} y_{t-m}+\sum_{1}^{d} \delta_{j} x_{t}+\sum_{1}^{5} \gamma_{v} Z_{t}+\varepsilon_{t}
$$

where the variables denote: $y_{t}$, the two-day changes of the variable under consideration (spread for government bonds, bank bonds, and corporate bonds); $x_{t}$ includes the control variables (where the control is set for week-calendar days); $Z_{t}$, represents the five dummy variables identifying each monetary policy event; $\varepsilon_{t}$, a random shock; $\alpha$, represents the constant in the regression; $\beta_{i}(i=1 \ldots m)$, the coefficients referring to the respective lags of the variable $y_{t} ; \delta_{j}(j=1 \ldots d)$, the coefficients corresponding to the control variables; $\gamma_{v}(v=1 \ldots 5)$, the coefficients of the dummies of the five identified events.

\subsection{Results}

The results of the regressions are presented in Tables 2-4 only with respect to the coefficients that relate to the events identified.

Table 2 shows the impact of the events on the relevant spreads in the banking sector. The first two columns relate to the spread at 1-month and 3-month maturities,

\footnotetext{
${ }^{20}$ The Datastream mnemonic for the bank bond index is IBCBANK (IBoxx index), which aggregates bonds at different maturities.

${ }^{21}$ The Datastream mnemonic for the corporate bond index is IBCB10, which aggregates bonds at different maturities.
} 
Table 2 Effects on banks' spreads

\begin{tabular}{llll}
\hline & 1-month spread & 3-month spread & Long-term spread \\
\hline 12 March 2020 & $-0.01^{* * *}$ & $-0.02^{* *}$ & $-0.09^{* *}$ \\
18 March 2020 & $-0.01^{* * *}$ & $-0.02^{*}$ & 0.03 \\
30 April 2020 & $0.02^{* * *}$ & 0.00 & 0.00 \\
29 October 2020 & $0.01^{* * *}$ & 0.00 & -0.01 \\
10 December 2020 & 0.00 & 0.00 & 0.00 \\
Obs & 521 & 520 & 519 \\
$\mathrm{R}^{2}$ & 0.23 & 0.38 & 0.67
\end{tabular}

$p$-values are in brackets. ${ }^{* * *} p<0.01 ; * * p<0.05 ;{ }^{*} p<0.1$

while the last column refers to the long-term spread. Notice that the estimated parameters of the regression (see Eq. 1) capture the short-term impact, on a two-day horizon, that the various events examined had on the change of the spread. A coefficient of 0.01 , for example, denotes that the event increased the spread after two days by $0.01 \%$, Using this metric, the table shows that the monetary policy event identified only displayed marginal impacts on the change of the relevant spreads for banks.

The table shows that the strengthening of the T-LTRO III (12 March 2020) represented the ECB policy initiative that had the most important impact in reducing spreads along all considered time horizons. In particular, the long-term spreads decreased by almost ten basis points. The other events did not display a comparable impact on spreads. In some cases, they just provided a marginal impact on short-term maturities.

More interesting results will be obtained if we look at the spreads for government bond yields. This is shown in the first and second columns of Table 3, which display, respectively, the composite EA and the Italian government spreads. The last column reports, instead, the effects on spreads of corporate bond yields. The results for the events of 12 and 18 March 2020, are shown to be significant and drastic.

Table 3 Effects on firms' and governments' yield spreads

\begin{tabular}{llll}
\hline & EZ sovereign spread & Italian sovereign spread & $\begin{array}{l}\text { Corporate bond } \\
\text { spread }\end{array}$ \\
\hline 12 March 2020 & $0.11^{* * *}$ & $0.28^{* * *}$ & -0.02 \\
18 March 2020 & $-0.23^{* * *}$ & $-0.77^{* * *}$ & 0.04 \\
30 April 2020 & $0.01^{* * *}$ & 0.00 & 0.01 \\
29 October 2020 & $-0.02^{* * *}$ & $-0.05^{* * *}$ & $0.01^{* * *}$ \\
10 December 2020 & 0.00 & $0.02^{* *}$ & $-0.01^{* *}$ \\
Obs & 522 & 522 & 518 \\
$\mathrm{R}^{2}$ & 0.36 & 0.33 & 0.62 \\
\hline
\end{tabular}

$p$-values are in brackets. $* * * p<0.01 ; * * p<0.05 ; * p<0.1$ 
The ECB's monetary policy decisions and announcements of 12 March 2020 significantly contributed to the increase of government bond yield spreads on that day and on the following two days. This specifically applies to the Italian spread, which is estimated to have increased by 28 basis points after the event of 12 March. The main culprit is President Lagarde's famous statement at the Press Conference. As already mentioned, Ms. Lagarde said that the ECB's role was not to close sovereign debt spreads. Indeed, as Table 3 shows, the market well understood the message; and the impact of this message was not compensated for by the strengthening of the T-LTRO III. However, our analysis cannot exclude that investors were also disappointed by the modest one-off $€ 120$ billion strengthening of the APP. By contrast, on 18 March 2020 the ECB launched the PEPP with a total envelop of $€ 750$ billion. This event reduced significantly government bond yield spreads, especially for Italy. The effect was significant since it amounted to 77 basis points. Interestingly, as noted in Sect. 4, the downward pressure on spreads became more effective after some time, perhaps suggesting the importance of enacting additional channels or policies.

The announcement on 29 October 2020 of the future strengthening of the ECB's expansionary monetary policy, showed a relatively weak impact: a 5-basis-point reduction of government bond yield spread for Italy and an even lower reduction for the EA. However, on 10 December 2020, the robust implementation of this announcement apparently had no effect at all. At first glance, this empirical result is difficult to explain. It signals that, in fact, positive announcements do not have the same impact as actual positive initiatives; however, financial investors incorporate news in their market behaviour so that the announcements can reduce the impact of the implementation of these policies due to the absence of market surprise.

The third column of Table 3 shows that the examined monetary policy events only marginally affected spreads in the corporate bond markets. Interestingly, the controversial announcement on 12 March did not completely blur the positive effects of the ECB's actual decisions on corporate bonds. In other words, the strengthening of the T-LTRO III was interpreted by potential borrowers as a positive news regarding the interest rate structure. However, the impact was small and not significant (only 2-basis points); hence, it does not allow for a robust interpretation.

Let us finally focus on expectation dynamics of inflation rates. In Table 4 we apply an econometric analysis to Eq. (1) by using measures of inflation expectations captured by the spread between nominal and real yields and the swap rates at the same maturity. We consider 5 and 10 -year inflation expectations. ${ }^{22}$

Even in this case, the impact of the announcements on inflation expectations was limited. Interestingly in some cases the responses went in the opposite direction with respect to what the economic intuition should have suggested. For example, President Lagarde's announcement of 12 March 2020 had a deflationary content; on the contrary, the whole event produced an increase in inflation expectations probably ascribable to the expected impact of the strengthened T-LTRO III. Moreover, the event on 18 March should have boosted inflation expectations rather than implying a persistent

${ }_{22}$ Market-based expectation data have been obtained from Datastream. 
Table 4 Effect on inflation expectations

\begin{tabular}{lll}
\hline & 5-year horizon & 10-year horizon \\
\hline 12 March 2020 & $0.02^{* * * *}$ & $0.04^{* * *}$ \\
18 March 2020 & 0.01 & $-0.05^{* * *}$ \\
30 April 2020 & $0.01^{*}$ & $0.01^{*}$ \\
29 October 2020 & $0.02^{* * *}$ & $0.02^{* * *}$ \\
10 December 2020 & $-0.01^{* *}$ & $-0.01^{* * *}$ \\
Obs & 522 & 520 \\
$\mathrm{R}^{2}$ & 0.48 & 0.48 \\
\hline
\end{tabular}

$p$-values are in brackets. $* * * p<0.01 ; * * p<0.05 ; * p<0.1$

decline. A caveat to be considered for explaining these results is that market-based measures of inflation expectations may not be appropriate for measuring the significant inflation expectations for economic agents' consumption and investment decisions. Most importantly, they may react only slowly to new information as agents process their long-term economic impact. As shown in Sect. 4, the agents' reaction started to head in the expected direction, with delay.

\subsection{Limits}

An event-study analysis is characterised by some structural limitations that would be appropriate to emphasise. First, in examining the ECB's decisions to change its monetary policy stance, it would be necessary to verify if the event was not anticipated by the market. A partial or full anticipation could result from information leaks or simply from the market agents' ability to read some signals of the possible ECB measures before their implementation. In these cases, the event-study analysis could still capture some surprise in the actual disclosure of the decision with respect to the previous market information set; however, the surprise and its impact would be weakened. The same applies to the announcements. It is important to verify that the latter were not fully anticipated by the market; otherwise, their possible impact would be cancelled. The second limitation of an event-study analysis derives from the possible time coincidence in the disclosure of different decisions and announcements. It is difficult to disentangle the specific impact of the various components in the consequent flow of contradictory information. For instance, in our exercise we analyse the impact of a specific event on the two-day changes of variables under examination; hence, it is impossible to specify the effects of each of the different decisions and announcements given on the same event day.

Event \#1 of Table 1 is a proper example of this second limitation. On that date, the ECB strengthened some aspects of the T-LTRO III and enlarged - even if mildly - the APP; afterward, during the Press Conference Ms. Lagarde announced that closing the spreads in sovereign debt markets was not consistent with the ECB's role. ${ }^{23}$

\footnotetext{
23 The ECB also decided to leave unchanged the interest rates on the main refinancing operations, the marginal lending facility, and the deposit facility.
} 


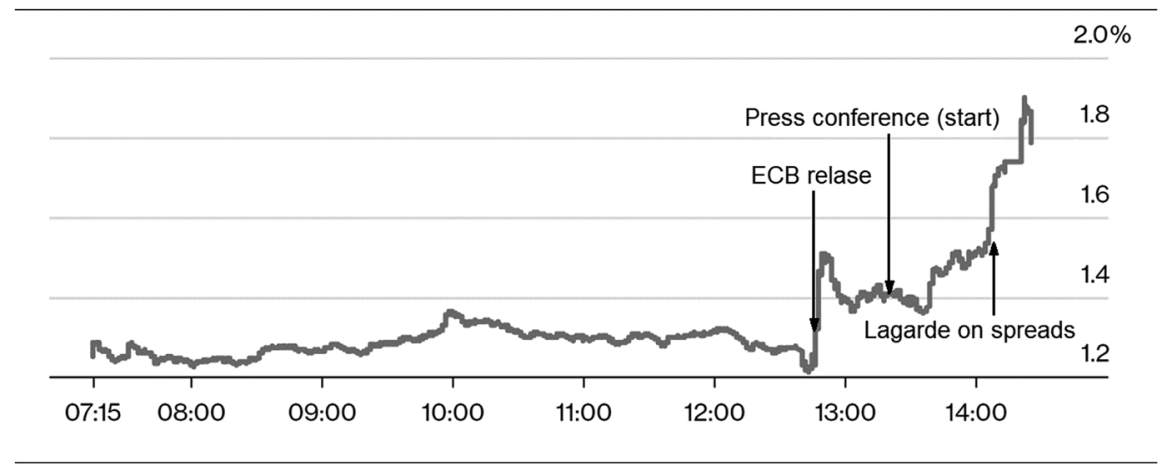

Source: Bloomberg

Fig. 2 Italian ten-year sovereign bond yield (12 March 2020; GMT)

Figure 2 clearly illustrates how complex was the impact of this event by plotting the 10 -year Italian government bond yield in different points in time. At the instant in which the ECB disclosed the information on the monetary policy decisions (12:45 GMT), the market yield on Italian debt had already jumped. This was probably due to the ECB's expansionary initiatives being weaker than generally expected. In the instant in which the Press Conference started (13:30 GMT), the yield progressively increased and jumped even further after the instant of Ms. Lagarde's statement.

\section{Conclusions}

By investigating the impact of the ECB's 2020 monetary policy decisions implemented to contrast the negative impact of the pandemic shock, this paper shows that these policies obtained limited but significant positive results.

In 2020, European firms and households experienced the dramatic consequences of the most severe economic and social crisis of the last two centuries. However, the huge amount of liquidity pumped by the ECB into the economic system through the monetary channel (APP and PEPP) reduced the risk of general economic breakdowns and social collapse by allowing also the most fragile countries of the EA to implement national expansionary fiscal policies despite their very limited fiscal capacity. The even larger amount of liquidity temporarily transferred by the ECB to the European banking sector decreased the number of firms and households hit by the quantity credit rationing and helped their temporary solvency. Hence, the ECB's extraordinary monetary policy contributed to overcoming the emergency. The continuation of this policy in 2021 and its combination with a centralised and expansionary fiscal policy (Next Generation - EU) has allowed EA countries to overcome the negative economic impact of further waves of Covid-19 while laying the foundation for an economic recovery that aims at implementing sustainable long-term development. 
The evolution of this new European 'policy mix' is still uncertain. It is worth stressing that the centralised fiscal policy launched in the EA and EU in the spring of 2020 and mainly implemented in the fall of 2021 is extraordinary and temporary. The initiatives, financed by the main EU programme (RRF), should be centred on projects (that is, a combination of reforms and public and private investments) relating to three pillars: 'green' transition, digital innovation, and social inclusion. All these projects should be concluded by the end of 2026. This means that, in the short term, the RRF will imply a deep restructuring of the EU production sectors and dramatic changes in the composition of the demand for capital equipment and human resources. To handle these profound economic changes, the RRF and other EU funds will not be sufficient, which is why European financial and non-financial firms will still need the support of an expansionary monetary policy. In its meeting of mid-December 2021, the ECB Governing Council stated that the increase in the EA's inflation rate is temporary and that the 2021 economic rebound is just a comforting basis for a robust recovery. Hence, the ECB confirmed the expansionary stance of its monetary policy. However, it also decided on a strong slowdown of its unconventional programmes.

It is difficult to forecast today (December 2021) the trend in the ECB's monetary policy in 2022. The parallel decision taken by the US central bank (the Fed) to conclude its pandemic emergency programme of asset purchases and to increase its policy interest rate will likely imply that, at the end of 2022, the ECB will take analogous decisions. In that case, the EA countries with high public debt/GDP ratio would be unable to reproduce a national expansionary fiscal policy. Hence, the EU's economic recovery and medium-term growth would be based on the successful implementation of the RRF and, specifically, on the efficient and effective management of the difficult economic transition. Moreover, these achievements could reproduce and strengthen the centralisation of EU fiscal policy beyond 2026 . Hence, the crucial question is: Is it possible that, thanks to the positive incidence of a centralised fiscal policy, the ECB's monetary policy becomes more prudent without penalising European growth?

Let us add that, even if the ECB was able to implement a persistent expansionary monetary policy, the long-term impact of the latter on national fiscal policies and on the implementation of the RRF's projects would remain unclear. EU countries would clearly face an easier centralised fiscal constraint. Can we maintain that the majority of national policymakers would use this opportunity to efficiently support the future economic development of their economies so that increases in the national government debts would not threaten their future sustainability? We cannot answer the last question by means of a positive and unqualified answer.

Our open conclusion is that the European economic evolution can establish several different equilibria (e.g. De Grauwe and Ji 2012). The continuation of an appropriate policy mix at the European level will be a crucial but insufficient condition to select a 'good' equilibrium and avoid 'bad' equilibria. Another condition will be an efficient national fiscal policy in the EA countries with high public debt/GDP ratios. 
Acknowledgements This paper is based on a study prepared for the European Parliament's Committee on Economic and Monetary Affairs (ECON) for the Monetary Dialogue of 18 March 2021 with the President of the European Central Bank, as part of a series of papers on "Recalibrated Monetary Policy Instruments to Address the Economic Fallout from COVID-19". The authors thank Urszula Szczerbowicz for suggestions and Serge Tseytlin for assistance.

\section{References}

Altavilla C, Giannone D (2017) The effectiveness of non-standard monetary policy measures: Evidence from survey data. J Appl Economet 32(5):952-964

Baker S, Bloom N, Davis SJ (2016) Measuring economic policy uncertainty. Quart J Econ 131(4):1593-1636

Basu S, Bundick B (2017) Uncertainty shocks in a model of effective demand. Econometrica 85(3):937-958

Benigno P, Canofari P, Di Bartolomeo G, Messori M (2020) Uncertainty and the pandemic shocks. Study for the Committee on Economic and Monetary Affairs, Policy Department for Economic, Scientific and Quality of Life Policies, European Parliament, Luxembourg

Bernanke BS, Kuttner N (2005) What explains the stock market's reaction to Federal Reserve Policy? J Finance 60(3):1221-1257

Bloom N (2014) Fluctuations in uncertainty. J Econ Perspect 28(2):153-176

Borri N, Di Giorgio G (2021) Systemic risk and the COVID challenge in the European banking sector. J Bank Finance, forthcoming

Campbell JR, Evans CL, Fisher JD, Justiniano A (2012) Macroeconomic effects of FOMC forward guidance. Brook Papers Econ Act Spring:1-54

De Grauwe P, Ji Y (2012) Mispricing of sovereign risk and multiple equilibria in the Eurozone. CEPS Pol Document 361

de Jong F, Kemna F, Kloek T (1992) A contribution to event study methodology with an application to the Dutch stock market. J Bank Finance 16(1):11-36

Draghi M (2014) Luncheon address: Unemployment in the Euro Area. Re-evaluating Labor Market Dynamics, Proceedings, Federal Reserve Bank of Kansas City, Jackson Hole, 295-318

ECB (2020) Economic Bulletin. 5

Ederington L, Guan W, Yang LZ (2015) Bond market event study methods. J Bank Finance 58:281-293

Gagnon J, Raskin M, Remasche J, Sack B (2011) The financial market effects of the Federal Reserve's large-scale asset purchases. Int J Cent Bank 7:3-43

Gertler M, Karadi P (2015) Monetary policy surprises, credit costs, and economic activity. Am Econ J Macroecon 7(1):44-76

Gorodnichenko Y, Weber M (2016) Are sticky prices costly? Evidence from the stock market. Am Econ Rev 106(1):165-199

Gortsos CV, Ringe WG (2020) Pandemic crisis and financial stability. Eur Bank Institute, Frankfurt

Gürkaynak RS, Sachs BP, Swason ET (2007) Market-based measures of monetary policy expectations. J Bus Econ Stat 25(2):201-212

Hamilton JD, Wu JC (2012) The effectiveness of alternative monetary policy tools in a zero lower bound environment. J Money, Credit, Bank 44:3-46

Krishnamurthy A, Vissing-Jorgensen A (2011) The effects of quantitative easing on interest rates: channels and implications for policy. Brook Papers Econ Act Fall:215-287

Kuttner KN (2018) Outside the box: Unconventional monetary policy in the Great Recession and beyond. J Econ Perspect 32(4):121-146

Lagarde C (2020a) Monetary Policy in a Pandemic Emergency. Keynote speech by Christine Lagarde, President of the ECB, at the ECB Forum on Central Banking, Frankfurt am Main

Lagarde C (2020b) The Monetary policy strategy review: Some preliminary considerations. Speech at the "ECB and Its Watchers XXI" Conference

Lane PC (2020a) Monetary policy in a pandemic: Ensuring favourable financing conditions. Speech by Philip R. Lane, Member of the Executive Board of the ECB, at the Economics Department and IMTCD, Trinity College Dublin

Lane PC (2020b) The ECB's monetary policy in the pandemic: Meeting the challenge. Speech by Philip R. Lane, Member of the Executive Board of the ECB, at the 62nd NABE Annual Meeting Global Reset? Economics, Business, and Policy in the Pandemic 
Loipersberger F (2018) The effect of supranational banking supervision on the financial sector: Event study evidence from Europe. J Bank Finance 91:34-48

MacDonald M, Popiel MK (2020) Unconventional monetary policy in a small open economy. Open Econ Rev 31:1061-1115

Miller M (2021) Choosing the narrative: the shadow banking crisis in light of Covid. Open Econ Rev 32:291-310

Miyajima H, Yafeh Y (2007) Japan's banking crisis: An event-study perspective. J Bank Finance 31(9):2866-2885

Morelli P, Segnezza E (2021) Why was the ECB's reaction to Covid-19 crisis faster than after the 2008 financial crash? J Pol Model 43(1):1-14

Neri S, Siviero S (2018) The non-standard monetary policy measures of the ECB: Motivations, effectiveness and risks. Credit and Capital Markets 51:513-560

Rogers JH, Scotti C, Wright JH (2014) Evaluating asset-market effects of unconventional monetary policy: A multi-country review. Econ Pol 29(80):749-799

Rostagno M, Altavilla C, Carboni G, Lemke W, Motto R, Guilhem AS, Yiangou J (2019) A tale of two decades: The ECB's monetary policy at 20. ECB Work Paper No. 2346

Sun R (2020) Monetary policy announcements and market interest rates' response: Evidence from China. $\mathrm{J}$ Bank Finance, forthcoming

Swanson ET (2011) Let's twist again: A high-frequency event-study analysis of Operation Twist and its implications for QE2. Brook Papers Econ Act 151-188

Swanson ET (2021) Measuring the effects of Federal Reserve forward guidance and asset purchases on financial markets. J Monet Econ 118:32-53

Szczerbowicz U (2015) The ECB unconventional monetary policies: Have they lowered market borrowing costs for banks and governments? Int J Cent Bank 11(4):91-127

Visco I (2019) The euro-area economy and the recent monetary policy decisions. Giornate di economia "Marcello De Cecco" Lanciano, Italy

Wright JH (2012) What does monetary policy do to long-term interest rates at the zero lower bound? Econ J 122(564):F447-F466

Publisher's Note Springer Nature remains neutral with regard to jurisdictional claims in published maps and institutional affiliations. 